\title{
A Comparative Study of the Interaction of Different Polycyclic Aromatic Hydrocarbons on Different Types of Single Walled Carbon Nanotubes
}

\author{
Sourabhi Debnath \\ Technological University Dublin, Sourabhi.debnath@tudublin.ie \\ Qiaohun Cheng \\ Technological University Dublin, qiaohuan.cheng@tudublin.ie \\ Theresa Hedderman \\ Technological University Dublin, Theresa.Hedderman@tudublin.ie \\ Follow this and additional works at: https://arrow.tudublin.ie/nanolart \\ See next page for additional authors \\ Part of the Nanoscience and Nanotechnology Commons
}

\section{Recommended Citation \\ Debnath, S. et al. (2010) A Comparative Study of the Interaction of Different Polycyclic Aromatic Hydrocarbons on Different Types of Single Walled Carbon Nanotubes. Journal of Physical Chemistry C, Vol.114, (18), pp.8167-8175. 2010. doi:10.1021/jp1001644}

This Article is brought to you for free and open access by the NanoLab at ARROW@TU Dublin. It has been accepted for inclusion in Articles by an authorized administrator of ARROW@TU Dublin. For more information, please contact arrow.admin@tudublin.ie, aisling.coyne@tudublin.ie,gerard.connolly@tudublin.ie. Funder: Science Foundation Ireland Research Frontiers Program PHY037 2006. The Raman Instrument was purchased under the framework of the INSPIRE programme, funded by the Irish Government's Programme for Research in Third Level Institutions, Cycle 4, National Development Plan 2007-2013, supported by the European Union Structural Fund.

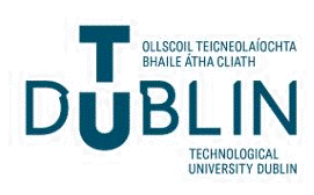




\section{Authors}

Sourabhi Debnath, Qiaohun Cheng, Theresa Hedderman, and Hugh Byrne

This article is available at ARROW@TU Dublin: https://arrow.tudublin.ie/nanolart/33 


\title{
A comparative study of the interaction of different
}

\section{polycyclic aromatic hydrocarbons on different types of single walled carbon nanotubes.}

\author{
Sourabhi Debnath*, Qiaohuan Cheng, Theresa G. Hedderman, and Hugh J. Byrne
}

FOCAS Research Institute, Dublin Institute of Technology, Kevin Street, Dublin 8, Ireland

* Corresponding author. Tel: +353 1402 7932. Fax: +35314027901.

E-mail: sourabhi.debnath@dit.ie.

\section{ABSTRACT}

A comparative study of the solubilising effect of polycyclic aromatic hydrocarbon (PAHs) on single walled carbon nanotubes (SWCNTs) produced by high pressure decomposition of carbon monoxide (HiPco) and the arc discharge (AD) method has been carried out with the aid of fluorescence and Raman spectroscopy. For this study, polyphenyl and polyacene PAHs of different lengths are used. From the study it has been found that the binding energy of PAHs with AD SWCNTs is the same as that with HiPco SWCNTs. Shorter PAHs molecules better solubilise SWCNTs and in general smaller diameter SWCNTs. Thus, given their smaller diameter profile, significantly larger amounts of HiPco SWCNTs are solubilised than AD SWCNTs. 
KEYWORDS: Single walled carbon nanotubes, polycyclic aromatic hydrocarbon, fluorescence quenching, binding energy, dispersion limit.

\section{INTRODUCTION}

Single walled carbon nanotubes (SWCNTs) are one of the most studied nano-materials due to their high strength [1], electrical[2] and thermal conductivity [3]. These SWCNTs can be produced by arc discharge (AD) [4, 5], laser ablation (LA) [2, 6, 7], high pressure decomposition of carbon monoxide (HiPco) [8], and catalytic decomposition of hydrocarbons [9]. In bulk production, SWCNTs produced by different processes contain bundles and ropes of SWCNTs with significant quantities of impurities. For many application purposes it is important to disperse SWCNTs from their bundles and remove impurities. But due to their relative insolubility in solvents, non reactive surfaces, in combination with their high surface area and high aspect ratio which leads to significant agglomeration via intrinsic intertubule van der Waals attractions, it is difficult to process and handle them [10]. Various methods have been reported for the solubilisation and dispersion of SWCNTs in water and organic solvents [1112]. It has been found that SWCNTs can be solubilised in water with linear polymers; polyvinyl pyrrolidone (PVP) and polystyrene sulfonate (PSS) [19]. It is also reported that in water SWCNTs have been dispersed with the aid of surfactant [20]. Functionalization also increases the solubility of SWCNTs $[16,21]$ in water and organic solvents.

It has been also found that organic polymers such as poly PmPV-co-DOctOPV and polycyclic aromatic hydrocarbons (PAHs) can solubilise and aid in the purification of the SWCNTs in organic solvents $[12-15,18]$. The interaction can cause the SWCNTs to disperse from their bundled form [12$15,18]$ and there is a strong suggestion that the organic species interact preferentially with SWCNTs of certain diameters or diameter range and even electronic structure $[12,13,22]$. In other studies it was found that adsorption of specifically designed and geometrically constrained pentacenic and quaterrylene based amphiphiles was found to be selective of the nanotube helicity angle [23]. 
To optimise the solubilisation and dispersion of SWCNTs in solvents using PAHs, it is important to understand the interaction of SWCNTs with PAHs. In a previous study, the interaction of PAHs with SWCNTs produced by the HiPco process was studied in a systematic way using PAHs of different lengths from the polyacene and polyphenyl series $[14,15]$. From this study, clear structure property relationships governing the binding energies of the molecules to the HiPco SWCNTs and the dispersion limit of HiPco SWCNTs in the composite solutions $[14,15]$ were obtained. From a Raman spectroscopy study, a limited degree of structural specificity was evident, although PAHs were seen to solubilise both chiral and achiral HiPco SWCNTs [24].

The objective of the study presented here is to explore the interaction of these PAHs of systematically varied chain length with SWCNTs produced by the HiPco and AD methods, exploring the significance of the diameter and length of SWCNTs on the interaction of PAHs with SWCNTs. For this study, fluorescence and Raman spectroscopy were used. For the fluorescence study, a model based on the adsorption/desorption equilibrium of SWCNTs and PAHs has been used [11]. The details of this method are described elsewhere $[11,14,15,17,22]$. It probes the interaction of the PAH molecules with the SWCNTs bundles and their resultant dispersion into isolated nanotubes by monitoring fluorescence quenching as a function of concentration. It yields a characteristic concentration $\left(C_{0}\right)$ at which the rate of adsorption of PAH molecules onto the SWCNT surfaces is equal to the desorption rate, which is in turn dependent on the molecular binding energy, $E_{B}$. The effect of systematic variation of PAH length and structure on $C_{0}$ and $E_{B}$ can lay the foundation for structure activity relationships.

The diameter dependent selective interaction of both types of SWCNTs with the PAH molecules is studied by Raman spectroscopy. Raman spectroscopy is a powerful tool to investigate the vibrational properties and thus characterize SWCNTs. The radial breathing modes (RBMs) of SWCNTs which lie in the region of $\sim 200 \mathrm{~cm}^{-1}$ give information about the diameter and chirality of SWCNTs. In this region, 
carbon atoms undergo uniform radial displacement [25-27]. As the RBM frequency is related to the SWCNT diameter and the structural indices $(n, m)$, a Raman spectrum of a SWCNT sample can be employed to establish the range of diameters present in a sample [28]. It was recognised at an early stage that, for a given sample of SWCNTs containing a range of diameters, the Raman spectrum is dominated by the SWCNT which are resonant at the frequency of the source laser [28]. Thus, for the complete characterisation of a sample of SWCNT, a broad range of laser excitation energies should be used [26]. To investigate the interaction of different PAHs with HiPco and AD SWCNTs, the Raman spectra were recorded with four different laser excitation energies. Employing these four different laser excitation energies, the range of SWCNT diameters within the pristine SWCNTs and composite samples were obtained. Comparing the diameter distribution of composite samples to those of pristine samples the information about selective interaction of different PAHs with HiPco and AD SWCNTs were obtained. Combining the fluorescence and Raman studies, a quantitative assessment of the relative efficacy of PAHs in solubilising SWCNTs made by the two production methods is made.

\section{EXPERIMENTAL SECTION}

As received HiPco SWCNTs obtained from Carbon Nanotechnologies, Inc. (16200 Park Row, Houston, TX 77087), AD SWCNTs (Sigma-Aldrich, Ireland) and PAHs (Sigma-Aldrich, Ireland), were used to prepare different composite solutions with chloroform as solvent. HiPco SWCNTs typically contain up to $10 \%$ metal catalyst (Fe) impurities, encapsulated in the tips $[8,29]$, and AD SWCNTs up to $30 \%$ amorphous carbon or turbostratic graphite and catalyst impurities $[5,30]$. Chloroform was used because of its poor affinity for SWCNTs $[11,31]$. Although, a small degree of solubilisation is affected at low concentration[32], precipitation is observed within hours of sonication. In the presence of PAHs, however, the solutions are stable for more than 24 months.

Two sets of solutions (the ranges are provided below) were prepared. To one of the two sets, HiPco SWCNTs were added in a 1:1 ratio by weight (w/w); HiPco SWCNTs: PAHs. 
$\sim 1.25 \times 10^{-3} \mathrm{~mol} / \mathrm{L}$ to $\sim 1.22 \times 10^{-6} \mathrm{~mol} / \mathrm{L}$ for naphthalene,

$\sim 7.81 \times 10^{-5} \mathrm{~mol} / \mathrm{L}$ to $\sim 3.72 \times 10^{-11} \mathrm{~mol} / \mathrm{L}$ for tetracene,

$\sim 1.56 \times 10^{-4} \mathrm{~mol} / \mathrm{L}$ to $\sim 1.19 \times 10^{-9} \mathrm{~mol} / \mathrm{L}$ for biphenyl and

$\sim 7.81 \times 10^{-5} \mathrm{~mol} / \mathrm{L}$ to $\sim 3.63 \times 10^{-14} \mathrm{~mol} / \mathrm{L}$ for $p$-quaterphenyl

At the highest concentration, both PAHs and composite solutions were sonicated using a sonic tip (Ultrasonic processor VCX $750 \mathrm{~W}$ ) for $3 \times 10 \mathrm{~s}$ at $38 \%$ of the power output. Then these samples were serially diluted by a factor of two with pure chloroform down to the lowest concentration. Each diluted sample was further tip sonicated as above and was then allowed to settle for 72 hours, after which the supernatant liquid from the composite samples was carefully withdrawn. The suspensions were allowed to settle for a further 24 hours before being characterized by fluorescence spectroscopy (Perkin Elmer LS55). The same procedures and concentration ranges as above were used to prepare composites of AD SWCNTs with the corresponding PAHs.

It was noted that for both HiPco SWCNTs and AD SWCNTs composites, in suspensions above the dispersion limit, described below, a considerable amount of precipitation of SWCNTs was observed and so the solubilisation is only partial. The dispersion limit is the concentration where SWCNTs are maximally dispersed [20, 23]. At concentrations where the SWCNTs are well dispersed, no precipitate was found. As composite solutions were prepared by using SWCNTs/PAHs in 1:1 ratio by weight (w/w), it can be stated that below the dispersion limit the concentration of PAHs and SWCNTs are the same. Concentrations quoted are thus those of the as prepared solutions in terms of PAH concentration.

From fluorescence studies, the regions where SWCNTs were dispersed to a maximum in the presence of PAHs of different lengths were obtained. At these concentrations, the SWCNTs bundles were fully dispersed. The concentration range was chosen such that it spanned the region of dispersion 
observed in these fluorescence based studies $[14,15]$. The sample below the dispersion limit $[14,15,20$, 33] (Table 4) for each PAH composite was chosen for Raman characterization and was drop cast onto clean quartz substrates. AFM confirmed that at concentration below the dispersion limit, the bundles remained isolated on the substrate (supplemental information Figure S1).

The Raman instrument used in this study was a LabRAM HR 800 Raman Microscope (Horiba Jobin Yvon) with a confocal imaging microscope system. Four laser lines, $785 \mathrm{~nm}(\sim 1.58 \mathrm{eV})$ at 240 $\mathrm{mW}, 660 \mathrm{~nm}(\sim 1.88 \mathrm{eV})$ at $80 \mathrm{~mW}, 532 \mathrm{~nm}(\sim 2.33 \mathrm{eV})$ at $40 \mathrm{~mW}$ and $473 \mathrm{~nm}(\sim 2.62 \mathrm{eV})$ at $40 \mathrm{~mW}$ were employed as sources. To study the effect of PAH length on solubility and selectivity of SWCNTs, the four laser lines were used to extensively probe the range of diameters present in the composite samples. Spectra were acquired by mapping the $25 \mu \mathrm{m} \times 25 \mu \mathrm{m}$ field of view of a x50 long focal length objective with a step size of $5 \mu \mathrm{m}$. By scanning two different areas within the samples, on average fifty spectra for each sample were obtained. Raman spectra were corrected for the quartz substrate background. The RBM features obtained were fitted with a combination Lorentzian/Gaussian line shape using the instrument LabSpec software version 4.02.

\section{RESULTS AND DISCUSSION}

Before studying the interaction of different PAHs with HiPco and AD SWCNTs using the

fluorescence model, pristine SWCNTs were characterised using Raman spectroscopy. Figure 1 shows the Raman spectra in the RBM region of a pristine HiPco and AD SWCNTs sample for the four different laser sources; $785 \mathrm{~nm}(1.58 \mathrm{eV}), 660 \mathrm{~nm}(1.88 \mathrm{eV}), 532 \mathrm{~nm}(2.33 \mathrm{eV})$ and $473 \mathrm{~nm}(2.62 \mathrm{eV})$. Due to the different resonance conditions [34], each different source wavelength gives rise to a markedly different profile and these profiles are also very different for HiPco and AD SWCNTs. Figure 1 (ii) and 
(iv) show the combined profiles of RBMs with the four different laser energies of HiPco and AD SWCNTs respectively by a simple addition of the respective spectra which have been normalized according to the intensities of the RBMs of each laser line for pristine HiPco and AD SWCNTs respectively.

Using a previously reported method [24], the diameter distribution of pristine HiPco and AD SWCNTs were obtained (Table 1 and 2). From Table 1 and 2 and Figure 1, it is found that the SWCNTs used for the interaction study were of diameter ranges from $\sim 0.7 \mathrm{~nm}$ to $\sim 1.4 \mathrm{~nm}$ and from $\sim 1.3 \mathrm{~nm}$ to $\sim$ $1.7 \mathrm{~nm}$ for HiPco and AD SWCNTs respectively. These diameter ranges are consistent with reported values of HiPco ( $0.7 \mathrm{~nm}$ to $1.4 \mathrm{~nm}[8])$ and AD SWCNTs (1.1 nm to $1.74 \mathrm{~nm} \mathrm{[35])} \mathrm{obtained} \mathrm{by} \mathrm{TEM}$ and Raman studies respectively.

To study the interaction of PAHs with HiPco and AD SWCNTs, containing markedly different structural profiles, a fluorescence based model was employed. In SWCNTs/PAHs composite solutions, free PAHs molecules and those that are bound to the SWCNTs are present simultaneously [11]. In the composite solution, quenching of the fluorescence in the presence of SWCNTs relative to the fluorescence of PAH solutions in the absence of SWCNTs, indicates the interaction of PAHs with SWCNTs $[11,17,18,22,36]$. In the case of composite solutions, the observed fluorescence is due to the free molecules only. Adapting the fluorescence model of Coleman et al. [11], a plot of the fraction of free PAHs molecules as a function of concentration was achieved (Figure 2). This model is based on the adsorption and desorption of molecules in solution by the SWCNT surface at low concentration and when the system is in equilibrium, the adsorption rate equals the desorption rate [11]. According to this model, as the concentration is varied, the variation of the fraction of free molecules can be described in terms of a characteristic concentration [11] and the concentration of SCWNTs.

$$
\begin{array}{ll}
N_{\mathrm{F}} /\left(N_{\mathrm{F}}+N_{\mathrm{B}}\right)=1 /\left(1+C_{\mathrm{NT}} / C_{0}\right)=\mathrm{Fl}_{\text {comp }} / \mathrm{Fl}_{\text {polymer }} & \text { Equation 1 } \\
\text { where } C_{0}={ }^{2}{ }_{\text {bur }} A_{\text {bun }} \mathrm{e}^{-E / k T} /(48 D f) & \text { Equation 2 }
\end{array}
$$


In Equation 1, $C_{0}$ is the characteristic concentration as defined in reference [11] and $C_{\mathrm{NT}}$ is the concentration of SWCNTs. It represents the concentration at which the number of free molecules, $\mathrm{N}_{\mathrm{F}}$, is equal to the number of bound molecules, $N_{\mathrm{B}}$, and thus the concentration at which the rate of molecular adsorption on the SWCNT surfaces is equal to the rate of desorption. As SWCNTs and PAHs are used in a 1:1 ratio by weight, $C_{\mathrm{NT}}$ can also represent the concentration of the molecules. $N_{\mathrm{F}}$ is the number of free molecules, $N_{\mathrm{B}}$ is the number of bound molecules, $F l_{\text {comp }}$ is the fluorescence of the composite and $F l_{\text {polymer }}$ is the fluorescence of the polymer which gives the fraction of free molecules in solution. In Equation 2, is a pre-exponential frequency factor, bun is the SWCNT bundle mass density , $A_{\text {bun }}$ is the bundle surface area, $E_{\mathrm{B}}$ is the binding energy, $k$ is the Boltzmann constant, $T$ is the absolute temperature, $f$ is the spatial integral, $D$ is the diffusion coefficient and $D=k T /\left(\begin{array}{ll}6 & a\end{array}\right)$, where is the solvent viscosity and $a$ is the molecular hydrodynamic radius [11]. From Equation 2 the binding energy $E_{\mathrm{B}}$ between the molecules and the SWCNTs can be obtained [11].

In Figure 2, the curves show the same general trend regardless of the type of SWCNTs, in agreement with the behavior seen by Coleman et al. [11] and Hedderman et al. [22]. At the highest concentrations, shown in Figure 2 for the example of $p$-quaterphenyl only, the molecularly dispersed PAHs interact with SWCNT bundles. With decreasing concentration, the PAHs act to disperse the SWCNTs, decreasing the bundle size (as confirmed by AFM [11, 20, 22]), increasing the effective surface area per SWCNT available to the molecules for adsorption, resulting in a concentration dependent decrease in the fraction of free PAH molecules, as represented by the ratio of Equation 1. This decrease reaches a minimum at the point when the SWCNTs are maximally dispersed. Similar concentration dependent debundling has been observed and verified using AFM in organic solvents [33] and water/surfactant dispersions [20] of HiPco SWCNTs and the concentration of maximum dispersion has been termed the dispersion limit [20, 33]. In the plots of fluorescence quenching, the dispersion limit is determined by the concentration of maximum quenching. From this point, further decreasing the concentration, the surface area per SWCNT is constant and the fluorescence quenching behavior can be fitted by Equation 1 using $C_{0}$ (the 
characteristic concentration) as a fitting parameter. For the range of PAHs, it has been observed that the dispersion limit, or concentration of maximal fluorescence quenching, and the characteristic concentration $C_{0}$, are linearly correlated (supplemental information Figure S2).

Figure 3 shows the relationship between the estimated dispersion limit of HiPco and AD SWCNTs, and the molecular weight of PAHs. With increasing length of the PAH molecules the concentration at which SWCNTs bundles are maximally dispersed is reduced for both HiPco and AD SWCNTs. This is an indication that the shorter molecules are more effective at dispersing the SWCNTs bundles. The polyacene PAHs are more effective than their polyphenyl counterparts and this may be an indication that the more planar and rigid polyacenes are more effective at debundling than the polyphenyl oligomers in which the phenyl units are free to rotate relative to each other. From Figure 3 it can be seen that, except for the tetracene composite, the dispersion limits of AD SWCNTs estimated for the three different PAHs are almost identical to those estimated for HiPco SWCNTs with the corresponding PAHs.

It is worth noting that for the case of the interaction of tetracene with both types of SWCNTs, the observed minimum of the fluorescence curve is considerably less that for the other PAHs and occurs at a concentration which is lower than the fitted characteristic concentration. This implies that less than 50\% of the molecules are bound at the minimum and may indicate that tetracene is not very efficient at debundling SWCNTs in general, albeit slightly better for AD SWCNTs. The dispersion limit of AD SWCNTs by tetracene is higher than that for HiPco SWCNTs by tetracene.

The observed quenching of the fluorescence of the PAHs is a result of $\pi-\pi$ stacking interactions [18, 22] between SWCNTs and the PAH molecules. Figure 4 shows the relationship between the maximum quenching of PAHs with HiPco (squares) and AD (triangles) SWCNTs, and molecular weight of PAHs. Starting from high concentrations, the degree of quenching increases as the composite solutions are 
diluted, due to a progressive debundling and therefore increase of the effective area of the SWCNTs. This reaches a minimum when the SWCNTs are maximally debundled, whereafter the concentration dependence follows the trend predicted by Equation 1. Comparing the polyacene PAHs to their polyphenyl counterparts, significantly higher quenching is seen for the polyphenyl series, indicating that a significantly higher fraction of (bound) polyphenyl molecules are required to affect the debundling process. Comparing AD to HiPCo SWCNTs for a given PAH, the quenching observed for AD is consistently larger than for HiPco, indicating that a larger fraction of (bound) PAH molecules are required to affect debundling. Within a given series (e.g. polyacene/AD or polyphenyl/HiPco) the degree of maximal quenching observed decreases monotonically, indicating a consistent mode of action within a series. Notably, the binding energy for both PAHs has previously been demonstrated to be linearly dependent on molecular weight, indicating an approximately constant interaction per carbon or ring $[14,15]$.

Below the dispersion limit, the concentration dependent quenching curves are well fitted by Equation 1 and a value of the characteristic concentration $C_{0}$ derived. For the range of PAHs, it has been observed that the dispersion limit, or concentration of maximal fluorescence quenching, and the characteristic concentration $C_{0}$, are linearly correlated (data not shown). The values of $C_{0}$ are found to be consistently larger in the case of the AD tubes, however, although only marginally (Table 3).

In the previous study of HiPco SWCNTs, it was found that the binding energy between PAHs and HiPco SWCNTs increases almost linearly with increasing molecular weight of PAHs [14, 15]. A similar linear relationship was obtained by Chakarova et. al. [37] and Zacharia et. al. [38] from the interactions of PAHs with themselves and graphite using density functional theory and experimentally determined using thermal desorption spectroscopy. 
To establish the binding energy between PAHs and AD SWCNTs, the same fluorescence model is used $[11,14]$. The value of ${ }_{\text {bun }}$ for HiPco and AD SWCNTs is taken as $1.6 \times 10^{-3} \mathrm{Kg} / \mathrm{m}^{-3}$ and $1.33 \times 10^{-3}$ $\mathrm{Kg} / \mathrm{m}^{-3}$ respectively [39], the value of $A_{\text {bun }}$ is taken as $1.5 \times 10^{-15} \mathrm{~m}^{2}$ for HiPco and for AD it is $2.2 \times 10^{-15}$ $\mathrm{m}^{2}$ [39]. The value of other parameters is taken from literatures [11, 14, 39].

From Table 3 it can be found that regardless of SWCNT type, the binding energy between SWCNTs and corresponding PAH is the same. It can be thus be stated that the binding energy between SWCNTs (HiPco and AD) and PAHs is constant but due to the different dimensions of the respective SWCNTs, the Co value is slightly different (HiPco and AD SWCNTs) for the corresponding composite.

To probe the selective interaction of different PAHs with HiPco and AD SWCNTs, Raman spectroscopy was used. The concentrations of the composite samples selected for the Raman study are listed in Table 4.

In Figure 5 (i) and (ii), which are the examples of single point Raman spectra of HiPco /naphthalene composite samples at two different concentrations, it can be seen that above the dispersion limit at $1.17 \times 10^{-4} \mathrm{~mol} / \mathrm{L}$, HiPco SWCNTs remain bundled but below the dispersion limit $\sim 1.46 \times 10^{-5} \mathrm{~mol} / \mathrm{L}$ predominantly isolated SWCNTs are observed. The insets of these figures show the RBM region of the corresponding sample and are corrected for the quartz substrate background. As for pristine HiPco and AD SWCNTs, maps of the composite sample of HiPco and AD SWCNTs with different PAHs at concentrations below the dispersion limit were performed using the four laser sources. Although in all cases the RBM spectrum was predominantly singly featured, the spectral positioning varied significantly from point to point. Therefore, a histogram of occurrence of single RBM features at specific frequencies was constructed for each source wavelength. To understand the overall effect of these PAHs on the diameter distribution of both SWCNTs, histograms of overall diameter distribution of solubilised, dispersed and isolated HiPco and AD SWCNTs are plotted on the same plot (Figure 6). As the RBM 
frequency is inversely proportional to the diameter, in these plots the histograms represent the percentage of occurrences of SWCNTs of different diameters, for each composite, at each of the four different laser excitation energies.

It is well established that the diameter of SWCNT $(d)$ can be related to the RBM frequency $\omega_{R B M}$ and structural indices $(n, m)$ by the following equation [40]

$\omega_{R B M}=\frac{C_{1}}{d}+C_{2}=\frac{\pi C_{1}}{a_{c-c} \sqrt{3\left(n^{2}+n m+m^{2}\right)}}+C_{2} \ldots \ldots \ldots \ldots .$. Equation 3,

where,

$a_{c-c}$ is the distance between the C-C bonds, $0.144 \mathrm{~nm},[40]$

$C_{1}$ is a constant of proportionality [41],

$C_{2}$ is essentially a damping factor which accounts for a frequency shift dependent on the damping caused by the local environment of the SWCNT [34].

In literature, different values of $C_{1}$ and $C_{2}$ can be found, ranging from $216 \mathrm{~cm}^{-1} \mathrm{~nm}$ to $248 \mathrm{~cm}^{-1} \mathrm{~nm}$ and 10 to $19 \mathrm{~cm}^{-1}$ for $C_{1}$ and $C_{2}$ respectively [25-27, 40, 42-45]. Therefore there is considerable uncertainty in the selection of the value of these parameters. For the purpose of this work, two sets of $C_{1}\left(216 \mathrm{~cm}^{-1}\right.$ $\mathrm{nm}$ and $\left.234 \mathrm{~cm}^{-1} \mathrm{~nm}\right)$ and $C_{2}(17 \mathrm{~nm}$ and $10 \mathrm{~nm})$ values were used to initially obtain a potential diameter range for pristine SWCNTs. from the RBM frequencies and Equation 3. An estimate of the most probable diameters contributing to the Raman spectrum at each source wavelength was made, assuming that resonant SWCNTs dominate the Raman spectrum, by reference to the so-called Kataura plot [46] which graphically relates the optical transition energies of metallic and semiconducting SWCNTs with their diameters. For SWCNTs of diameter in the range of $\sim 0.7 \mathrm{~nm}$ to $\sim 1.4 \mathrm{~nm}$ (which is the typical diameter range for HiPco SWCNTs [8], only semiconducting SWCNTs should be resonant at a laser energy of $\sim 1.58 \mathrm{eV}(785 \mathrm{~nm})$. Therefore, for this laser energy only the diameters of semiconducting SWCNTs in the selected diameter range were chosen. However, in many cases there exists more than 
one candidate corresponding to the particular $\omega_{R B M}$. To assign a single diameter to a corresponding $\omega_{R B M}$, the inverse of these chosen diameters were plotted against the corresponding value of $\omega_{R B M}$. As there is a linear dependence between $\omega_{R B M}$ and the inverse diameter (1/d) [26], the plot should be a straight line. For a particular $\omega_{R B M}$, a particular diameter was selected from the best fit to the straight line. Also from this best fit, the value of $C_{1}$ and $C_{2}$ were found to be $221.5 \mathrm{~cm}^{-1} \mathrm{~nm}$ and $14.4 \mathrm{~cm}^{-1}$ respectively for $785 \mathrm{~nm}$ $(1.58 \mathrm{eV})$. Similarly, the diameters and the value of $C_{1}$ and $C_{2}$ for the different laser energies were found. The values of $C_{1}$ and $C_{2}$ thus obtained were $207.5 \mathrm{~cm}^{-1} \mathrm{~nm}$ and $29.1 \mathrm{~nm}$ for $660 \mathrm{~nm}(1.88 \mathrm{eV}), 233.0 \mathrm{~cm}^{-1}$ $\mathrm{nm}$ and $8.5 \mathrm{~nm}$ for $532 \mathrm{~nm}(2.33 \mathrm{eV})$ and $213.7 \mathrm{~cm}^{-1} \mathrm{~nm}$ and $22.7 \mathrm{~nm}$ for $473 \mathrm{~nm}(2.62 \mathrm{eV})$ laser frequency respectively.

Given the systematic structural dependence of the binding energy of PAHs to mixed SWCNT samples, it is reasonable to expect that the binding interaction should be optimal for a direct mapping of the PAH structure onto the linear backbone of matched SWCNT structures. However, a recent detailed study of their interaction with HiPco SWCNTs suggests a binding which is not specific to structure or chirality [24]. The results from this study are presented in Figure 6, and show that the PAHs interact with a range of HiPco SWCNT diameters. In terms of structural selectivity, it has been observed that for HiPco SWCNTs, only the polyacene moieties solubilise the armchair SWCNTs, although biphenyl also solubilises the $(11,0)$ and $(12,0)$ zig-zag SWCNTs [24]. The polyphenyl moieties do not solubilise the armchair SWCNTs. However, in none of the four composite samples is the solubilisation of nonchiral SWCNTs dominant [24]. In general a preference for smaller diameter SWCNTs is evident, although the longer PAHs have the capacity to solubilise larger diameter SWCNTs, due to their increased binding energy. This general trend is also seen in the interaction of PAHs of varying length with AD SWCNTs.

It must therefore be postulated that the smaller PAHs can relatively efficiently bind normal to the tube axis of nonchiral nanotubes and along the direction of the chiral vector of chiral nanotubes. Given the curvature of the SWCNTs, this is more efficient for the smaller PAHs on small diameter SWCNTs, the 
longer PAHs interacting more efficiently with larger diameter SWCNTs. Additionally, the polyphenyl PAHs have a degree of rotational freedom about the inter-phenyl bond which may inhibit structurally specific binding. PAHs are also known to stack orthogonal to the surface of graphite, although this is energetically favourable only at high coverage [38]. A correlation of such steric and energetic considerations may reduce any structural selectivity. The curvature of SWCNTs compared to the width of PAHs [47] and the solvent, chloroform [48] might also affect the interaction process. Gotovac et al. reported that in liquid-phase adsorption of tetracene and phenanthrene on SWCNTs, tetracene was adsorbed more than six times more than phenanthrene which attributed to the effect of the nanoscale curvature of the tube surface [47]. From the report of Liu et al.[48], it has been found that in liquidphase, the solvent also plays an important role for the selective solubilisation of SWCNTs. It was found that the pentacene derivative is more effective for extraction of metallic SWCNTs when dimethylfomamide (DMF) is used as a solvent rather than $N$-methyl-2-pyrrolidone (NMP) and chloroform [48].

From Figure 6, it is difficult to obtain quantitative information about the degree of solubilisation by the different PAHs. In this sense it would be more informative to estimate the number of SWCNTs solubilised at the characteristic concentration. From a previous study using AFM [39], the average diameter and length of HiPco and AD SWCNTs were found to be $0.9 \mathrm{~nm} ; 750 \mathrm{~nm}$ and $1.3 \mathrm{~nm} ; 1000 \mathrm{~nm}$ respectively. Using these values, the approximate volumes $\left(V_{\text {Tube }}=2 \quad \mathrm{r}^{2} 1\right.$, where $\mathrm{r}$ and 1 are the radius and the length of a SWCNT respectively) of corresponding SWCNTs were calculated. Using Equation 4, the approximate number of corresponding SWCNTs per concentration, at the characteristic concentration $C_{0}$ was calculated.

$$
\frac{\text { Number }}{\text { Concentration }}=\frac{V_{\text {Solution }} \times \text { Count } \%}{\rho \times V_{\text {Tube }}} \mathrm{Kg}^{-1} \mathrm{~m}^{3} \quad \text { Equation } 4
$$


Here, Number $=$ Number of SWCNTs,

$V_{\text {Solution }}=$ Volume of the solution

$\rho=$ mass density of corresponding SWCNTs (HiPco: $1.6 \times 10^{-3} \mathrm{Kg} / \mathrm{m}^{3}$ and

AD: $\left.1.33 \times 10^{-3} \mathrm{Kg} / \mathrm{m}^{3}\right)$

Concentration $=$ Characteristic concentration for the respective $\mathrm{PAH}$.

Count $\%$ is the occurrence obtained from the Raman spectroscopy study.

A plot of Number/Concentration as a function of $\omega_{R B M S}$ representing the diameter distribution of HiPco and AD composite solutions was plotted (Figure 7). It can be seen that the approximate number of selected HiPco SWCNTs per concentration is significantly higher than that of AD SWCNTs and again it is found that the shorter chain PAHs more efficiently solubilise and disperse the SWCNTs. The approximate number of SWCNTs selected by different PAHs was obtained by multiplying the Number/Concentration of different PAHs/SWCNTs composite samples of corresponding SWCNTs (Table 3) with value of $C_{0}$. A plot representing the approximate number of selected SWCNTs (HiPco and AD) by different PAHs is shown in Figure 8.

In Figure 8, it can be seen that with increasing molecular weight or size of PAHs, the number of solubilised SWCNTs decreases. The decrease is approximately exponential, and correlates well with the approximately exponential decrease of the dispersion limit, as shown in Figure 3 (and characteristic concentration) with molecular weight of PAH. It can be stated that although longer PAHs bind more strongly with SWCNTs they solubilise the SWCNTs less efficiently. Therefore, the shorter the PAHs molecules (here naphthalene) the better the solubilisation of SWCNTs. From Figure 7 and 8, it is also evident that the number of AD SWCNTs selected by PAHs is less than that of HiPco SWCNTs. The reason might be because of the larger diameter and length of AD SWCNTs as well as the larger bundle surface area than that of HiPco SWCNTs more PAHs are interacting with AD SWCNTs to make it soluble than that of HiPco SWCNTs which is also evident from the quenching study (Figure 4). 
The quality and nature of impurities present in SWCNTs might also affect the interaction process [49]. However, it has previously been indicated that the interaction of PAHs and organic polymers with SWCNT samples effectively purifies them as amorphous and graphitic residuals are not solubilised [12, 18]. However, as indicated in the experimental section, at concentrations where the SWNTs are well dispersed, no precipitate was visually observable, indicating that some degree of impurities may be present in the sample. It is not clear how their presence may effect the interaction process, but in a quantitative comparison they should be considered. The presence of $30 \%$ and $10 \%$ impurities in AD and HiPCo samples respectively should result in a reduction of $\mathrm{C}_{0}$ by a corresponding factor. A re-evaluation of the PAH binding energies results in values for the $\mathrm{AD}$ composites which are consistently $~ 5 \%$ than those for the HiPco composites, a difference which is with in the experimental errors of the measurement. In terms of number of nanotubes solubilised, a similar correction would result in a further reduction of the estimate of the number of $\mathrm{AD}$ nanotubes solubilised, relative to HiPco.

\section{CONCLUSIONS}

The concentration dependence fluorescence study shows that, in a 1:1 composite ratio by weight, HiPco and AD SWCNTs are debundled at similar concentrations by PAHs. Polyacene PAHs are more efficient than their polyphenyl counterparts and debundling is affected more readily in HiPco composites than in AD. The total amount of solubilised SWCNTs decreases with the increasing molecular weight of PAHs. Observed differences in characteristic concentration for the two types of nanotube are largely due to differing dimensions, and once the tubes are maximally debundled, the binding energy of PAHs is independent of nanotube type. For both tubes types, little or no structural selectivity is observed, although in general smaller diameter nanotubes are more effectively solubilised. 
Thus, once debundled, the smaller diameter HiPCo SWCNTs are solubilised to a significantly higher degree than the AD SWCNT samples.

\section{ACKNOWLEDGMENT}

This project is funded under the Science Foundation Ireland Research Frontiers Program PHY037 2006. The Raman Instrument was purchased under the framework of the INSPIRE programme, funded by the Irish Government's Programme for Research in Third Level Institutions, Cycle 4, National Development Plan 2007-2013, supported by the European Union Structural Fund.

\section{Supporting Information Available}

Figure S1 shows an AFM image of HiPco SWCNTs deposited on quartz from a $~ 9.536 \times 10^{-9} \mathrm{~mol} / \mathrm{L}$ HiPco/tetracene suspension in chloroform. This concentration is below the concentration of maximum fluorescence quenching of the HiPco/tetracene composite sample. From this figure it is evident that below this concentration, the samples contain dispersed and isolated SWCNTs of diameters in the range of $\sim 0.8$ to $\sim 1.0 \mathrm{~nm}$. This AFM result indicates that the probability of obtaining isolated SWCNTs below this concentration is high for the corresponding composite, and that this concentration may be considered to be the dispersion limit of the composite dispersions. This AFM result also confirms that after drop-casting and drying the dispersed samples, SWCNTs remain debundled.

As shown in Figure S2, the dispersion limit is well correlated with the characteristic concentration $\mathrm{C}_{0}$.

These materials are available free of charge via the Internet at http://pubs.acs.org. 

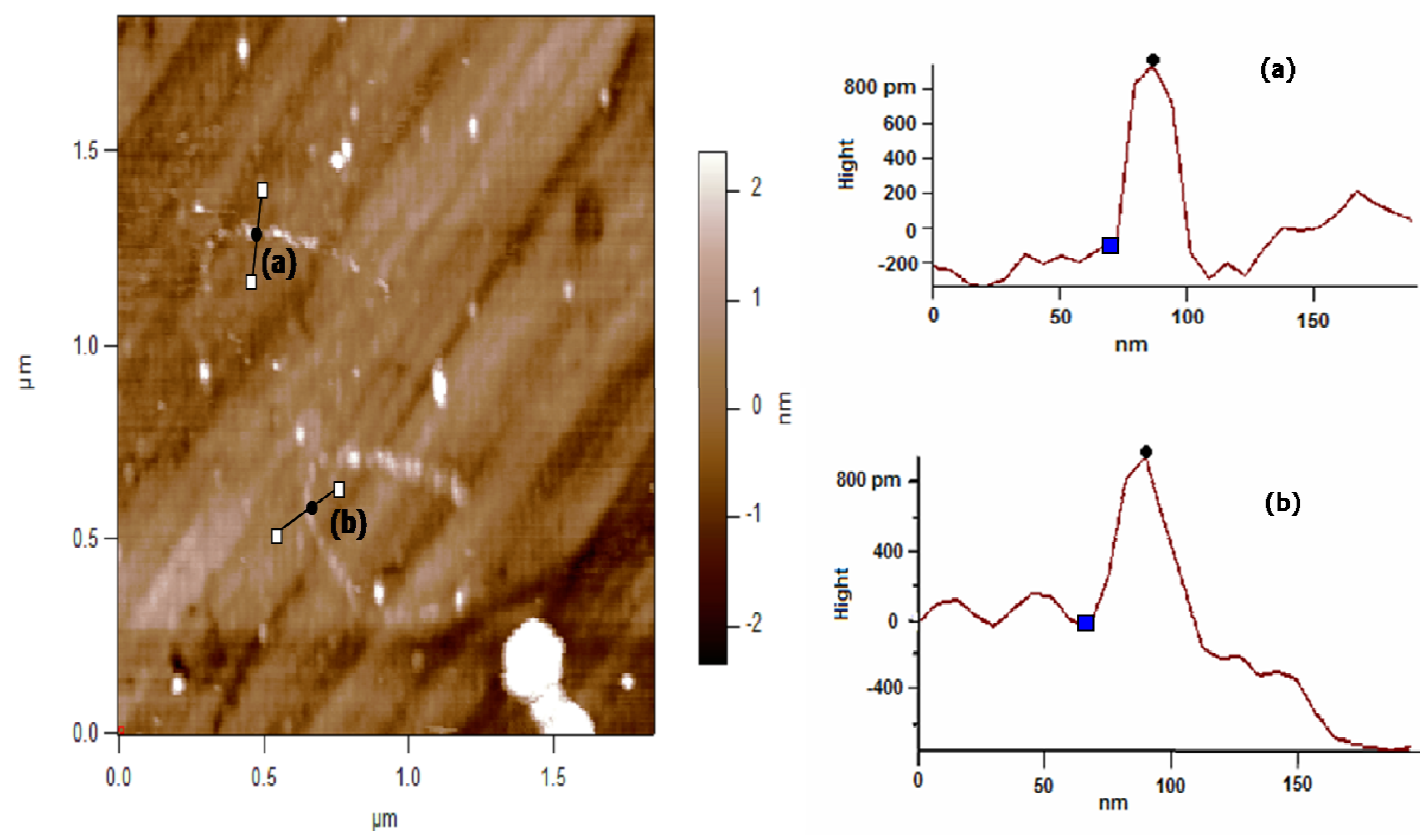

Figure S1: AFM image of HiPco SWCNTs of HiPco/tetracene sample at concentration $\sim 9.536 \times 10^{-9}$ mol/L (i). Diameters of HiPco SWCNTs in this sample are shown in (ii).

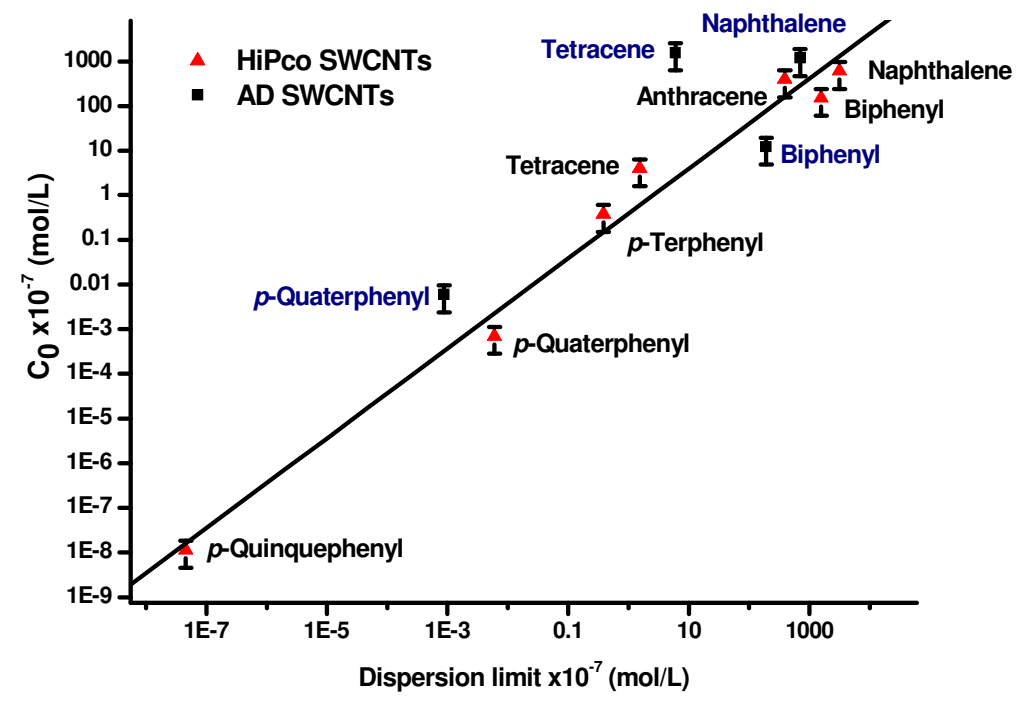

Figure S2: Characteristic concentration as a function of dispersion limit. 


\section{REFERENCES}

1. Yu, M.F.; Files, B.S.; Arepalli, S.; Ruoff, R.S. Tensile loading of ropes of single wall carbon nanotubes and their mechanical properties. Phys. Rev. Lett. 2000, 84, 5552-5555.

2. Thess, A.; Lee, R.; Nikolaev, P.; Dai, H.J.; Petit, P.; Robert, J.; Xu, C.H.; Lee, Y.H.; Kim, S.G.; Rinzler, A.G.; Colbert, D.T.; Scuseria, G.E.; Tomanek, D.; Fischer, J.E.; Smalley, R.E. Crystalline ropes of metallic carbon nanotubes. Science 1996, 273, 483-487.

3. Hone, J.; Whitney, M.; Piskoti, C.; Zettl, A. Thermal conductivity of single-walled carbon nanotubes. Phys. Rev. B 1999, 59, R2514-R2516.

4. Iijima, S.; Ichihashi, T. Single-Shell Carbon Nanotubes of 1-Nm Diameter. Nature 1993, 363, 603-605.

5. Journet, C.; Maser, W.K.; Bernier, P.; Loiseau, A.; delaChapelle, M.L.; Lefrant, S.; Deniard, P.; Lee, R.; Fischer, J.E. Large-scale production of single-walled carbon nanotubes by the electricarc technique. Nature 1997, 388, 756-758.

6. Puretzky, A.A.; Geohegan, D.B.; Fan, X.; Pennycook, S.J. Dynamics of single-wall carbon nanotube synthesis by laser vaporization. Appl. Phys. Mater. Sci. Process. 2000, 70, 153-160.

7. Scott, C.D.; Arepalli, S.; Nikolaev, P.; Smalley, R.E. Growth mechanisms for single-wall carbon nanotubes a laser ablation process. Appl. Phys. Mater. Sci. Process. 2002. 74, 11-11.

8. Nikolaev, P.; Bronikowski, M.J.; Bradley, R.K.; Rohmund, F.; Colbert, D.T.; Smith, K.A.; Smalley, R.E. Gas-phase catalytic growth of single-walled carbon nanotubes from carbon monoxide. Chem. Phys. Lett. 1999, 313, 91-97.

9. Colomer, J.F.; Bister, G.; Willems, I.; Konya, Z.; Fonseca, A.; Van Tendeloo, G.; Nagy, J.B. Synthesis of single-wall carbon nanotubes by catalytic decomposition of hydrocarbons. Chem. Commun. 1999, 1343-1344. 
10. Park, C.; Ounaies, Z.; Watson, K.A.; Crooks, R.E.; Smith, J.; Lowther, S.E.; Connell, J.W.; Siochi, E.J.; Harrison, J.S.; Clair, T.L.S. Dispersion of single wall carbon nanotubes by in situ polymerization under sonication. Chem. Phys. Lett. 2002, 364, 303-308.

11. Coleman, J.N.; Fleming, A.; Maier, S.; O'Flaherty, S.; Minett, A.I.; Ferreira, M.S.; Hutzler, S.; Blau, W.J. Binding kinetics and SWNT bundle dissociation in low concentration polymernanotube dispersions. J. Phys. Chem. B 2004, 108, 3446-3450.

12. Dalton, A.B.; Blau, W.J.; Chambers, G.; Coleman, J.N.; Henderson, K.; Lefrant, S.; McCarthy, B.; Stephan, C.; Byrne, H.J. A functional conjugated polymer to process, purify and selectively interact with single wall carbon nanotubes. Syn. Meta. 2001, 121, 1217-1218.

13. Dalton, A.B.; Stephan, C.; Coleman, J.N.; McCarthy, B.; Ajayan, P.M.; Lefrant, S.; Bernier, P.; Blau, W.J.; Byrne, H.J. Selective interaction of a semiconjugated organic polymer with singlewall nanotubes. J. Phys. Chem. B 2000, 104, 10012-10016.

14. Debnath, S.; Cheng, Q.; Hedderman, T.G.; Byrne, H.J. A study of the interaction between single-walled carbon nanotubes and polycyclic aromatic hydrocarbons: Toward structureproperty relationships. J. Phys. Chem. C 2008, 112, 10418-10422.

15. Debnath, S.; Cheng, Q.; Hedderman, T.G.; Byrne, H.J. An experimental study of the interaction between single walled carbon nanotubes and polycyclic aromatic hydrocarbons. Phys. Status Solidi B 2008, 245, 1961-1963.

16. Dyke, C.A.; Tour, J.M. Covalent functionalization of single-walled carbon nanotubes for materials applications. J. Phys. Chem. A 2004, 108, 11151-11159.

17. Giordani, S.; Bergin, S.D.; Drury, A.; Mhuircheartaigh, E.N.; Ruther, M.; Coleman, J.N.; Blau, W.J. Effect of solvent and dispersant on the bundle dissociation of single- walled carbon nanotube. Proc. SPIE 2005, 5824, 42-49.

18. Hedderman, T.G.; Keogh, S.M.; Chambers, G.; Byrne, H.J. Solubilization of SWNTs with organic dye molecules. J. Phys. Chem. B 2004, 108, 18860-18865. 
19. O'Connell, M.J.; Boul, P.; Ericson, L.M.; Huffman, C.; Wang, Y.H.; Haroz, E.; Kuper, C.; Tour, J.; Ausman, K.D.; Smalley, R.E. Reversible water-solubilization of single-walled carbon nanotubes by polymer wrapping. Chem. Phys. Lett. 2001, 342, 265-271.

20. Priya, B.R.; Byrne, H.J. Investigation of sodium dodecyl benzene sulfonate assisted dispersion and debundling of single-wall carbon nanotubes. J. Phys. Chem. C 2008, 112, 332-337.

21. Ren, D.M.; Guo, Z.; Du, F.; Liu, Z.F.; Zhou, Z.C.; Shi, X.Y.; Chen, Y.S.; Zheng, J.Y. A novel soluble Tin(IV) porphyrin modified single-walled carbon nanotube nanohybrid with light harvesting properties. Int. J. Mol. Sci. 2008, 9, 45-55.

22. Hedderman, T.G.; Keogh, S.M.; Chambers, G.; Byrne, H.J. In-depth study into the interaction of single walled carbon nanotubes with anthracene and p-terphenyl. J. Phys. Chem. B 2006, 110, 3895-3901.

23. Marquis, R.; Greco, C.; Sadokierska, I.; Lebedkin, S.; Kappes, M.M.; Michel, T.; Alvarez, L.; Sauvajol, J.L.; Meunier, S.; Mioskowski, C. Supramolecular discrimination of carbon nanotubes according to their helicity. Nano Lett. 2008, 8, 1830-1835.

24. Debnath, S.; Cheng, Q.; Hedderman, T.G.; Byrne, H.J. A Raman spectroscopy study of the solubilisation of SWCNTs by polycyclic aromatic hydrocarbons. Carbon December 2009, Accepted.

25. Bachilo, S.M.; Strano, M.S.; Kittrell, C.; Hauge, R.H.; Smalley, R.E.; Weisman, R.B. Structureassigned optical spectra of single-walled carbon nanotubes. Science 2002, 298, 2361-2366.

26. Dresselhaus, M.S.; Dresselhaus, G.; Jorio, A. Raman spectroscopy of carbon nanotubes in 1997 and 2007. J. Phys. Chem. C 2007, 111, 17887-17893.

27. Yu, Z.H.; Brus, L. Rayleigh and Raman scattering from individual carbon nanotube bundles. $J$. Phys. Chem. B 2001, 105, 1123-1134.

28. Rao, A.M.; Richter, E.; Bandow, S.; Chase, B.; Eklund, P.C.; Williams, K.A.; Fang, S.; Subbaswamy, K.R.; Menon, M.; Thess, A.; Smalley, R.E.; Dresselhaus, G.; Dresselhaus, M.S. 
Diameter-selective Raman scattering from vibrational modes in carbon nanotubes. Science 1997, 275, 187-191.

29. Carbon Nanotechnology Inc., 16200 Park Row, Houston, TX 77084-5195, United States.

30. http://www.sigmaaldrich.com.

31. Cheng, Q.; Debnath, S.; Gregan, E.; Byrne H.J. Effects of chlorinated aromatic solvents on the dispersion of HiPco SWNTs. Phys. Status Solidi B 2008, 245, 1947-1950.

32. Bahr, J.L.; Mickelson, E.T.; Bronikowski, M.J.; Smalley, R.E.; Tour, J.M. Dissolution of small diameter single-wall carbon nanotubes in organic solvents? Chem. Commun. 2001, 193-194.

33. Giordani, S.; Bergin, S.D.; Nicolosi, V.; Lebedkin, S.; Kappes, M.M.; Blau, W.J.; Coleman, J.N. Debundling of single-walled nanotubes by dilution: Observation of large populations of individual nanotubes in amide solvent dispersions. J. Phys. Chem. B 2006, 110, 15708-15718.

34. Kuzmany, H.; Plank, W.; Hulman, M.; Kramberger, C.; Gruneis, A.; Pichler, T.; Peterlik, H.; Kataura, H.; Achiba, Y. Determination of SWCNT diameters from the Raman response of the radial breathing mode. Euro. Phys. J. B 2001, 22, 307-320.

35. Keogh, S. Spectroscopic Characterisation of SWNT Polymer Composites. PhD thesis, Dublin Institute of Technology 2006.

36. Curran, S.A.; Ajayan, P.M.; Blau, W.J.; Carroll, D.L.; Coleman, J.N.; Dalton, A.B.; Davey, A.P.; Drury, A.; McCarthy, B.; Maier, S.; Strevens, A.; A composite from poly(mphenylenevinylene-co-2,5-dioctoxy-p-phenylenevinylene) and carbon nanotubes: A novel material for molecular optoelectronics. Adv. Mater. 1998, 10, 1091-1093.

37. Chakarova, S.D.; Schroder, E. van der Waals interactions of polycyclic aromatic hydrocarbon dimers. J. Chem. Phys. 2005, 122, 054102 (1)- 054102 (5).

38. Zacharia, R.; Ulbricht, H.; Hertel, T. Interlayer cohesive energy of graphite from thermal desorption of polyaromatic hydrocarbons. Phys. Rev. B 2004, 69, 155406-1-155406-7.

39. Hedderman, T.G. Solubilisation, purification and processing of SWNT using organic molecules. PhD Thesis. Dublin Institute of Technology 2006. 
40. Strano, M.S.; Doorn, S.K.; Haroz, E.H.; Kittrell, C.; Hauge, R.H.; Smalley, R.E. Assignment of (n, m) Raman and optical features of metallic single-walled carbon nanotubes. Nano Lett. 2003, 3, 1091-1096.

41. Hahm, M.G.; Kwon, Y.K.; Lee, E.; Ahn, C.W.; Jung, Y.J. Diameter Selective Growth of Vertically Aligned Single Walled Carbon Nanotubes and Study on Their Growth Mechanism. J. Phys. Chem. C 2008, 112, 17143-17147.

42. Fantini, C.; Jorio, A.; Souza, M.; Strano, M.S.; Dresselhaus, M.S.; Pimenta, M.A. Optical transition energies for carbon nanotubes from resonant Raman spectroscopy: Environment and temperature effects. Phys. Rev. Lett. 2004, 93, 147406(1)-147406(4).

43. Jorio, A.; Saito, R.; Hafner, J.H.; Lieber, C.M.; Hunter, M.; McClure, T.; Dresselhaus, G.; Dresselhaus, M.S. Structural (n, m) determination of isolated single-wall carbon nanotubes by resonant Raman scattering. Phys. Rev. Lett. 2001, 86, 1118-1121.

44. Rao, A.M.; Chen, J.; Richter, E.; Schlecht, U.; Eklund, P.C.; Haddon, R.C.; Venkateswaran, U.D.; Kwon, Y.K.; Tomanek, D. Effect of van der Waals interactions on the Raman modes in single walled carbon nanotubes. Phys. Rev. Lett. 2001, 86, 3895-3898.

45. Telg, H.; Maultzsch, J.; Reich, S.; Hennrich, F.; Thomsen, C. Chirality distribution and transition energies of carbon nanotubes. Phys. Rev. Lett. 2004, 93, 177401(1)-177401(4).

46. Kataura, H.; Kumazawa, Y.; Maniwa, Y.; Umezu, I.; Suzuki, S.; Ohtsuka, Y.; Achiba, Y.; Optical properties of single-wall carbon nanotubes. Syn. Meta. 1999, 103, 2555-2558.

47. Gotovac, S.; Honda, H.; Hattori, Y.; Takahashi, K.; Kanoh, H.; Kaneko, K. Effect of nanoscale curvature of single-walled carbon nanotubes on adsorption of polycyclic aromatic hydrocarbons. Nano Lett. 2007, 7, 583-587.

48. Liu, C.H.; Liu, Y.Y.; Zhang, Y.H.; Wei, R.R.; Li, B.R.; Zhang, H.L.; Chen, Y. Selective interaction of a soluble pentacene derivative with metallic single-walled carbon nanotubes. Chem. Phys. Lett. 2009, 471, 97-102. 
49. Gotovac, S.; Hattori, Y.; Noguchi, D.; Miyamoto, J.; Kanamaru, M.; Utsumi, S.; Kanoh, H.; Kaneko, K. Phenanthrene adsorption from solution on single wall carbon nanotubes. J. Phys. Chem. B 2006, 110, 16219-16224.

Table 1 RBM spectral positions and the corresponding structure assignments for pristine HiPco SWCNTs at different laser energy excitations.

\begin{tabular}{|c|c|c|c|c|c|c|c|}
\hline \multicolumn{2}{|c|}{$\begin{array}{l}785 \mathrm{~nm} \\
1.58 \mathrm{eV}\end{array}$} & \multicolumn{2}{|c|}{$\begin{array}{l}660 \mathrm{~nm} \\
1.88 \mathrm{eV}\end{array}$} & \multicolumn{2}{|c|}{$\begin{array}{l}532 \mathrm{~nm} \\
2.33 \mathrm{eV}\end{array}$} & \multicolumn{2}{|c|}{$\begin{array}{l}473 \mathrm{~nm} \\
2.62 \mathrm{eV}\end{array}$} \\
\hline $\begin{array}{l}\omega_{R B M s} \\
\left(\mathrm{~cm}^{-1}\right)\end{array}$ & $\begin{array}{l}d \\
(\mathrm{~nm})\end{array}$ & $\begin{array}{l}\omega_{R B M s} \\
\left(\mathrm{~cm}^{-1}\right)\end{array}$ & $\begin{array}{l}d \\
(\mathrm{~nm})\end{array}$ & $\begin{array}{l}\omega_{\mathrm{RBMs}} \\
\left(\mathrm{cm}^{-1}\right)\end{array}$ & $\begin{array}{l}d \\
(\mathrm{~nm})\end{array}$ & $\begin{array}{l}\omega_{R B M s} \\
\left(\mathrm{~cm}^{-1}\right)\end{array}$ & $\begin{array}{l}d \\
(\mathrm{~nm})\end{array}$ \\
\hline 207.6 & 1.145 & 180.2 & 1.375 & 182.4 & 1.349 & 180.9 & 1.335 \\
\hline 217.7 & 1.102 & 186.2 & 1.326 & 192.5 & 1.270 & 196.0 & 1.232 \\
\hline 227.7 & 1.032 & 193.6 & 1.260 & 213.7 & 1.125 & 204.8 & 1.169 \\
\hline 236.5 & 0.994 & 216.1 & 1.111 & 222.5 & 1.091 & 218.5 & 1.091 \\
\hline 249.6 & 0.936 & 224.0 & 1.068 & 233.2 & 1.038 & 229.3 & 1.038 \\
\hline 261.4 & 0.894 & 243.0 & 0.965 & 244.8 & 0.991 & 244.5 & 0.962 \\
\hline 269.9 & 0.873 & 250.0 & 0.936 & 254.0 & 0.952 & 258.4 & 0.901 \\
\hline \multirow[t]{5}{*}{307.1} & 0.757 & 254.7 & 0.915 & 268.3 & 0.901 & 271.1 & 0.858 \\
\hline & & 262.4 & 0.884 & 278.0 & 0.858 & 288.2 & 0.805 \\
\hline & & 281.8 & 0.828 & 295.9 & 0.805 & 305.5 & 0.757 \\
\hline & & 294.9 & 0.781 & 317.2 & 0.777 & 330.5 & 0.692 \\
\hline & & & & & & 338.7 & 0.678 \\
\hline
\end{tabular}


Table 2 RBM spectral positions and the corresponding structure assignments for pristine AD SWCNTs at different laser energy excitations.

\begin{tabular}{|c|c|c|c|c|c|c|c|}
\hline \multicolumn{2}{|l|}{$\begin{array}{l}785 \mathrm{~nm} \\
1.58 \mathrm{eV}\end{array}$} & \multicolumn{2}{|l|}{$\begin{array}{l}660 \mathrm{~nm} \\
1.88 \mathrm{eV}\end{array}$} & \multicolumn{2}{|l|}{$\begin{array}{l}532 \mathrm{~nm} \\
2.33 \mathrm{eV}\end{array}$} & \multicolumn{2}{|l|}{$\begin{array}{l}473 \mathrm{~nm} \\
2.62 \mathrm{eV}\end{array}$} \\
\hline $\begin{array}{l}\omega_{R B M s} \\
\left(\mathrm{~cm}^{-1}\right)\end{array}$ & $\begin{array}{l}d \\
(\mathrm{~nm})\end{array}$ & $\begin{array}{l}\omega_{R B M s} \\
\left(\mathrm{~cm}^{-1}\right)\end{array}$ & $\begin{array}{l}d \\
(\mathrm{~nm})\end{array}$ & $\begin{array}{l}\omega_{\mathrm{RBMs}} \\
\left(\mathrm{cm}^{-1}\right)\end{array}$ & $\begin{array}{l}d \\
(\mathrm{~nm})\end{array}$ & $\begin{array}{l}\omega_{R B M s} \\
\left(\mathrm{~cm}-^{-1}\right)\end{array}$ & $\begin{array}{l}d \\
(\mathrm{~nm})\end{array}$ \\
\hline 147.01 & 1.672 & 149.98 & 1.663 & 146.25 & 1.697 & 153.68 & 1.581 \\
\hline 151.62 & 1.621 & 159.34 & 1.545 & 157.21 & 1.563 & 161.90 & 1.508 \\
\hline 157.95 & 1.549 & 165.30 & 1.487 & 166.60 & 1.470 & 167.77 & 1.431 \\
\hline 163.74 & 1.487 & 169.70 & 1.435 & 172.25 & 1.411 & 176.19 & 1.356 \\
\hline 167.17 & 1.448 & $\begin{array}{l}173.54 \\
179.21 \\
188.01\end{array}$ & $\begin{array}{l}1.395 \\
1.354 \\
1.260\end{array}$ & $\begin{array}{l}176.35 \\
183.89 \\
190.98\end{array}$ & $\begin{array}{l}1.384 \\
1.321 \\
1.270\end{array}$ & 182.48 & 1.299 \\
\hline
\end{tabular}

Table 3 Parameters for the calculation of binding energy. 


\begin{tabular}{lllll}
\hline PAHs & $\begin{array}{l}\text { For HiPco } \\
\text { composite }\end{array}$ & $\begin{array}{l}\text { For } \\
\text { composite }\end{array}$ & $\begin{array}{l}\text { For HiPco } \\
\text { composite }\end{array}$ & $\begin{array}{l}\text { For } \\
\text { composite }\end{array}$ \\
& $C_{0}(\mathrm{Kg} / \mathrm{m} 3)$ & $C_{0}(\mathrm{Kg} / \mathrm{m} 3)$ & $\mathrm{E}_{\mathrm{B}}(\mathrm{eV})$ & $\mathrm{E}_{\mathrm{B}}(\mathrm{eV})$ \\
\hline Naphthalene & $7.68 \times 10^{-3}$ & $8.96 \times 10^{-3}$ & 0.46 & 0.46 \\
Anthracene & $3.11 \times 10^{-3}$ & ------------- & 0.49 & ------- \\
Tetracene & $9.13 \times 10^{-5}$ & $1.36 \times 10^{-4}$ & 0.58 & 0.58 \\
Biphenyl & $2.31 \times 10^{-3}$ & $2.92 \times 10^{-3}$ & 0.50 & 0.50 \\
$p$-terphenyl & $5.75 \times 10^{-7}$ & ------------- & 0.72 & ------ \\
$p$-quaterphenyl & $2.14 \times 10^{-8}$ & $2.69 \times 10^{-8}$ & 0.81 & 0.81 \\
$p$-quinquephenyl & $4 \times 10^{-16}$ & -------------- & 1.12 & -------- \\
\hline
\end{tabular}

Table 4 Concentration of each PAH composite used for Raman study.

\begin{tabular}{ll|l}
\hline \multirow{2}{*}{ PAH } & \multicolumn{2}{l}{ Sample concentration $(\mathrm{mol} / \mathrm{L})$} \\
\cline { 2 - 3 } & HiPco & AD \\
\hline Naphthalene & $\sim 1.17 \times 10^{-4}$ & $\sim 2.92 \times 10^{-5}$ \\
Tetracene & $\sim 1.46 \times 10^{-5}$ & \\
Biphenyl & $\sim 4.76 \times 10^{-9}$ & $\sim 1.90 \times 10^{-8}$ \\
$p$-Quaterphenyl & $\sim 3.72 \times 10^{-11}$ & $\sim 3.72 \times 10^{-11}$ \\
\hline
\end{tabular}


Figure 1: RBMs of pristine HiPco (i) and AD (iii) SWCNTs with $785 \mathrm{~nm}(1.58 \mathrm{eV}), 660 \mathrm{~nm}(1.88 \mathrm{eV})$, $532 \mathrm{~nm}(2.33 \mathrm{eV})$ and $473(2.62 \mathrm{eV})$ as source (ii) combined Raman spectra of HiPco (ii) and AD (iv) SWCNTs for the different lasers.

Figure 2: A plot of the fraction of free PAHs as a function of concentration for HiPco SWCNTs and AD SWCNTs composite. The solid and dashed curves are the best fits to Equation 1 for HiPco and AD SWCNTs respectively. Solid and dashed vertical lines indicate $C_{0}$ and the dispersion limit of SWCNTs for the case of $p$-quaterphenyl respectively.

Figure 3: A plot of estimated dispersion limit of HiPco (squares) and AD (triangles) SWCNTs as a function of molecular weight of PAHs. Straight line is a guide to the eye.

Figure 4: A plot of maximum quenching of PAHs with HiPco (squares) and AD (triangles) SWCNTs as a function of molecular weight of PAHs. Straight lines are guide to the eye.

Figure 5: Raman spectra of HiPco/naphthalene composite samples of concentrations (i) $\sim 1.17 \times 10^{-4}$ $\mathrm{mol} / \mathrm{Land}$ (ii) $\sim 1.46 \times 10^{-5} \mathrm{~mol} / \mathrm{L}$ respectively at $532 \mathrm{~nm}(2.33 \mathrm{eV})$

Figure 6: A plot of overall diameter distribution of HiPco and AD SWCNTs selected by PAHs.

Figure 7: A plot of Number/Concentration as a function of $\omega_{R B M S}$.

Figure 8: Total number of solubilised AD and HiPco SWCNTs as function of molecular weight of PAHs. 


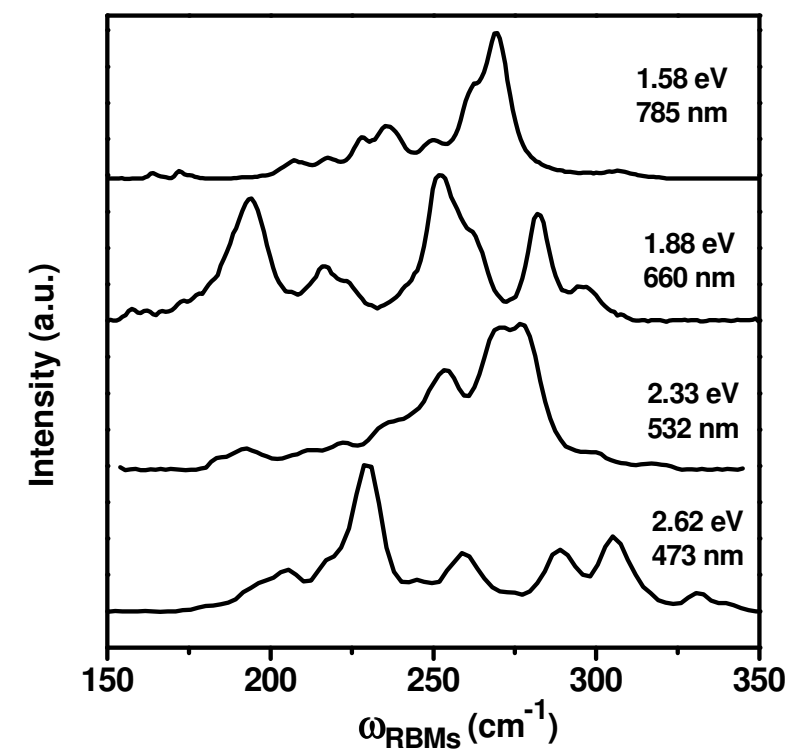

Figure 1 (i)

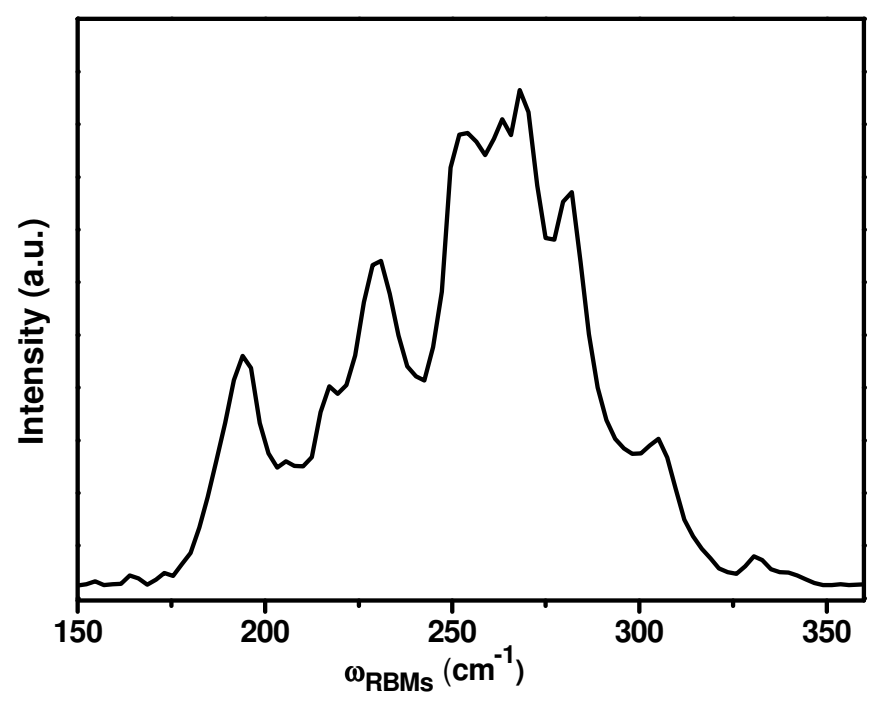

Figure 1 (ii) 


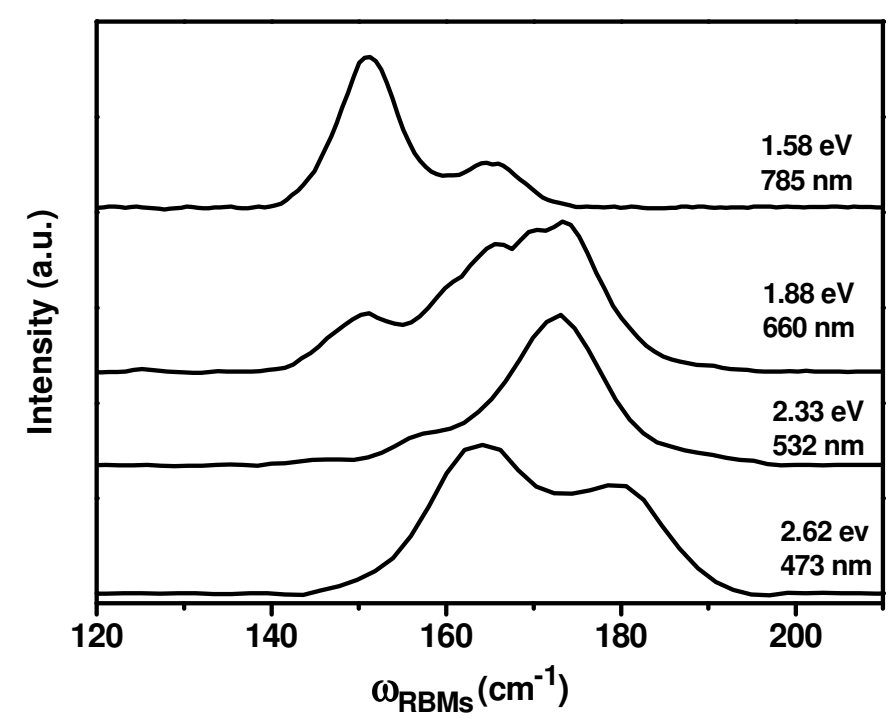

Figure 1 (iii)

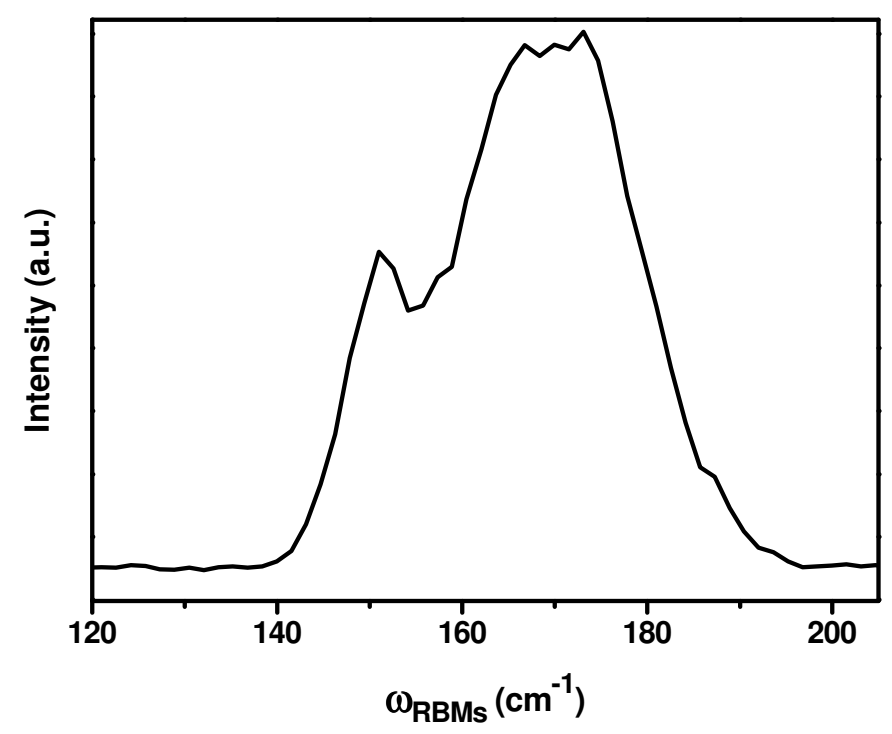

Figure 1 (iv) 


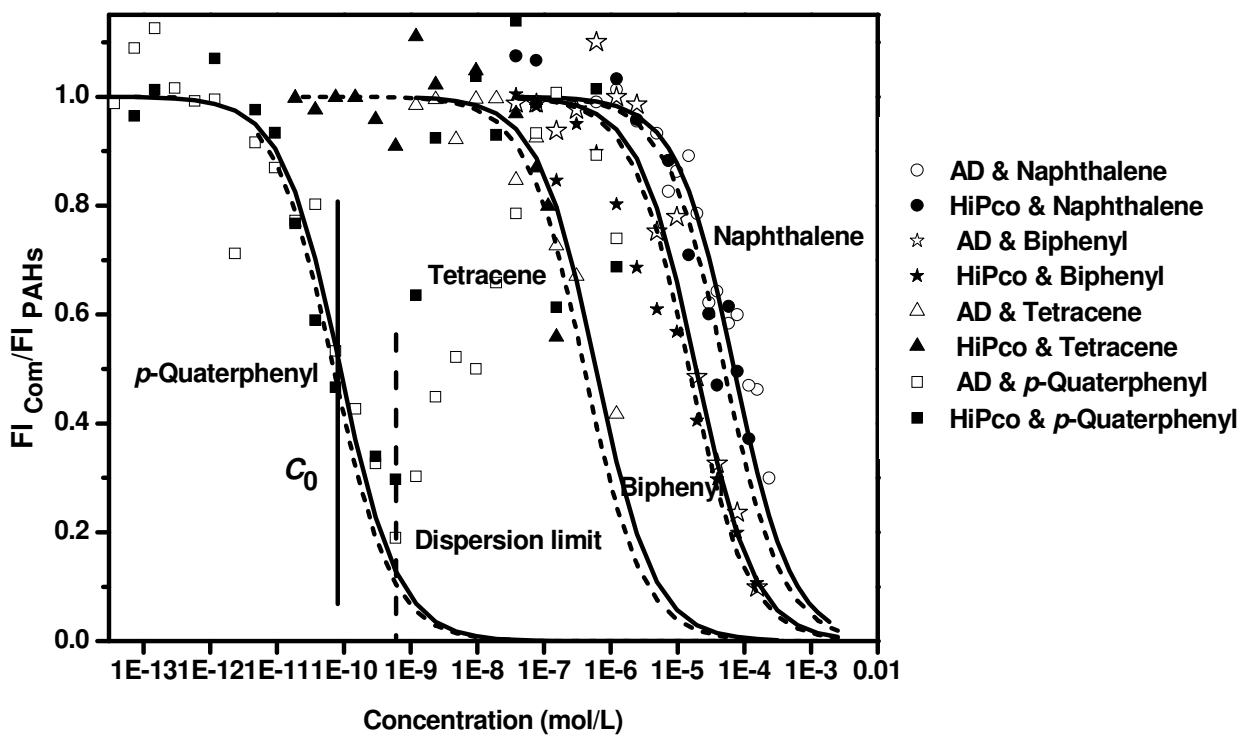

Figure 2

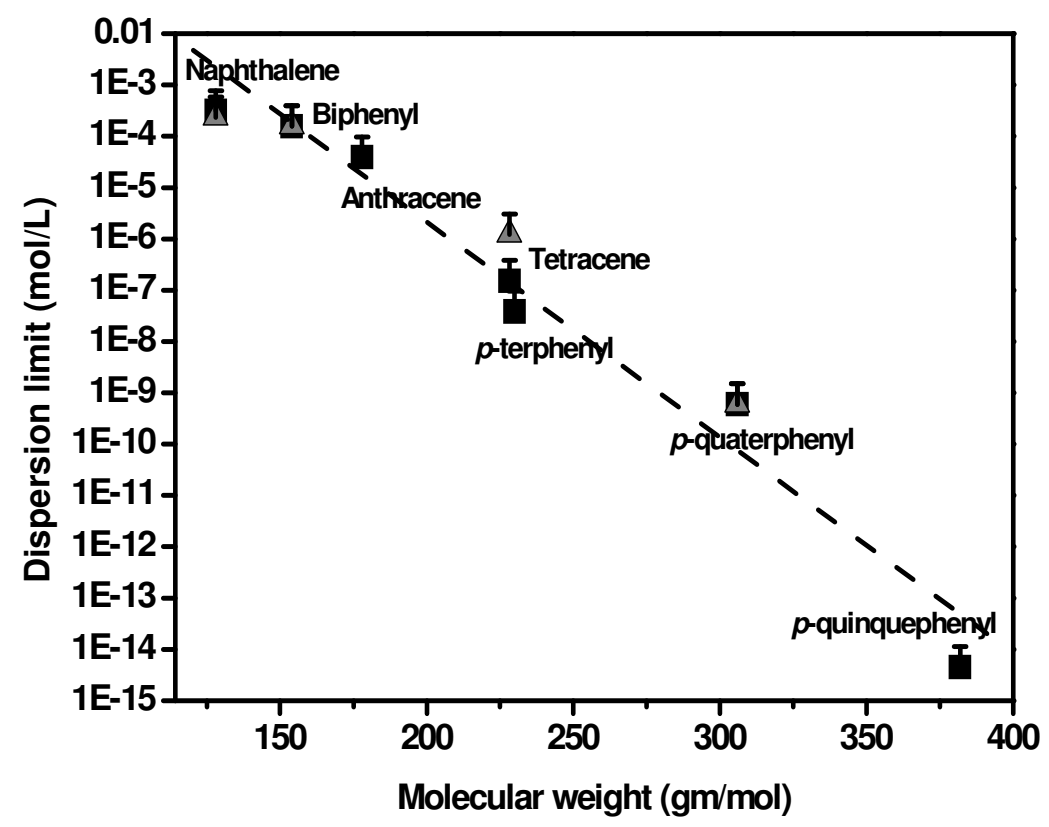

Figure 3 


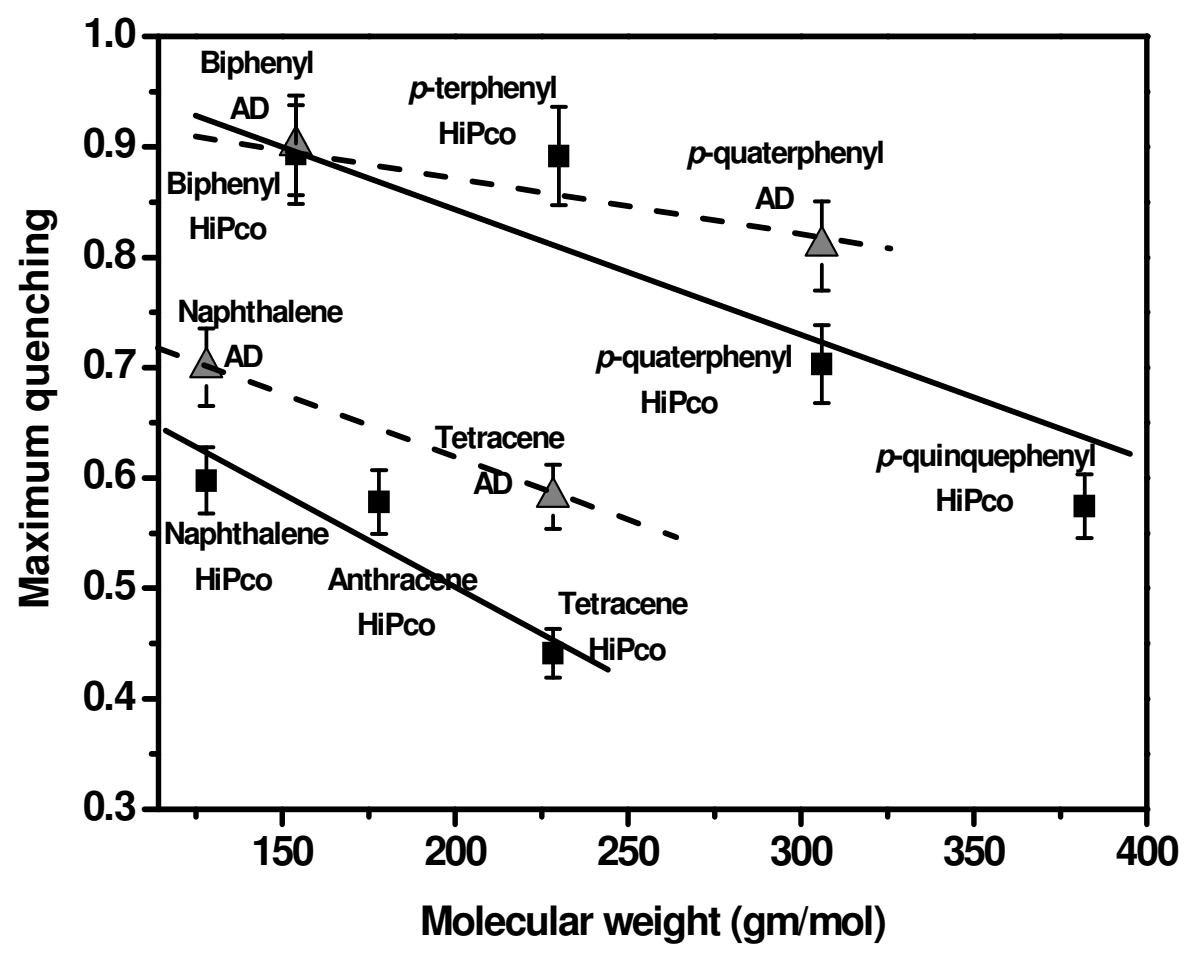

Figure 4

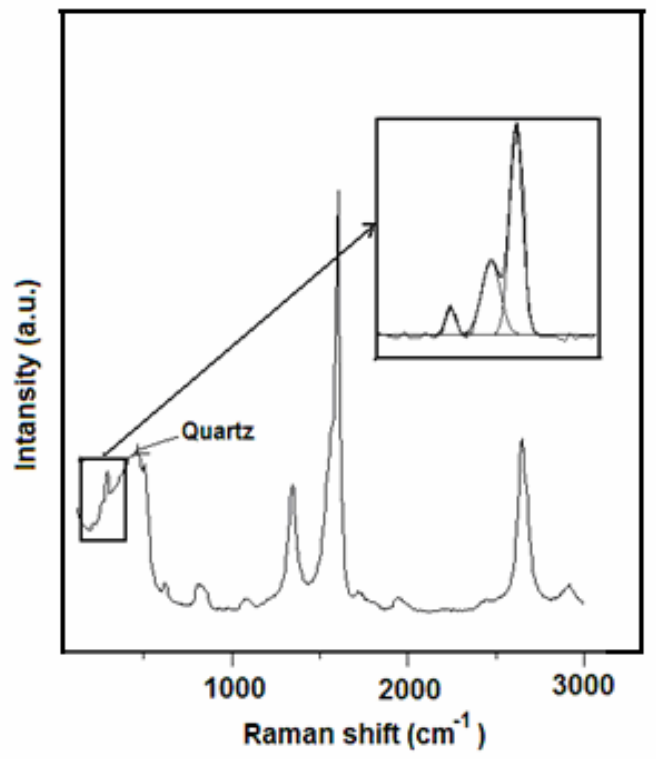

(i)

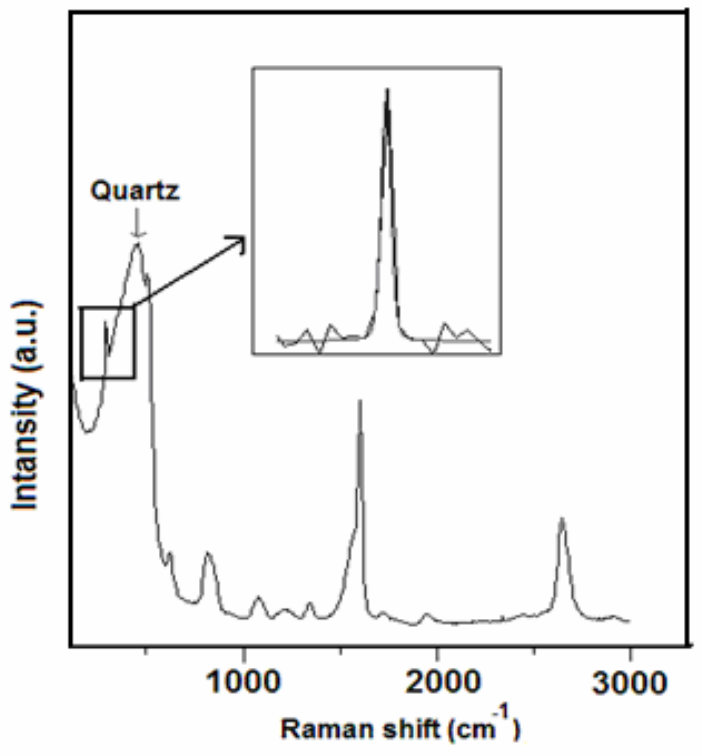

(ii)

Figure 5 


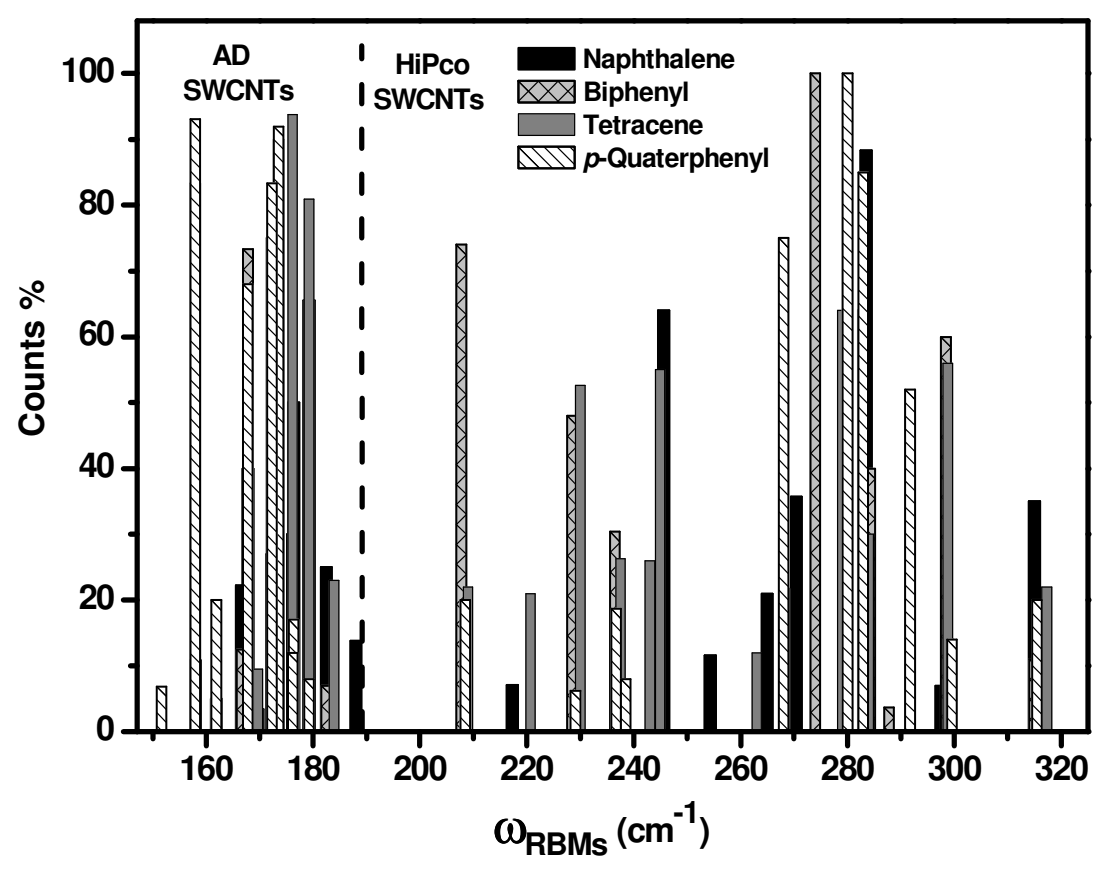

Figure 6

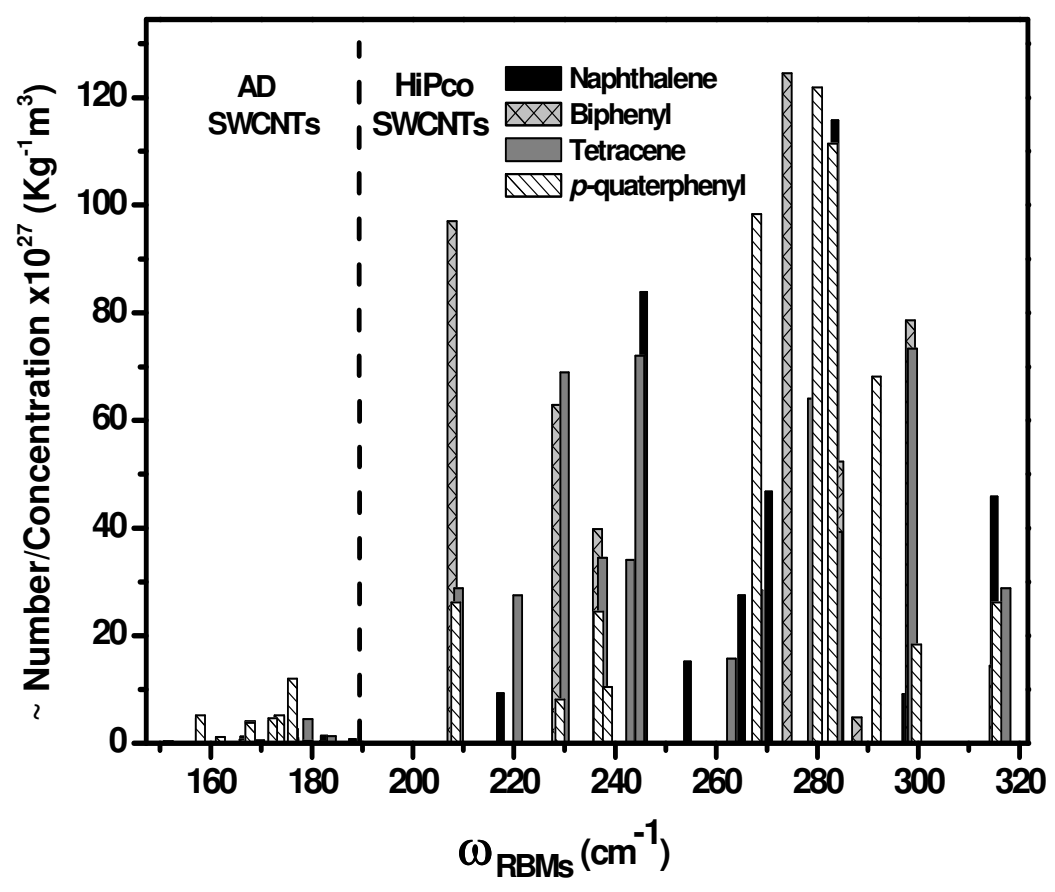

Figure 7 


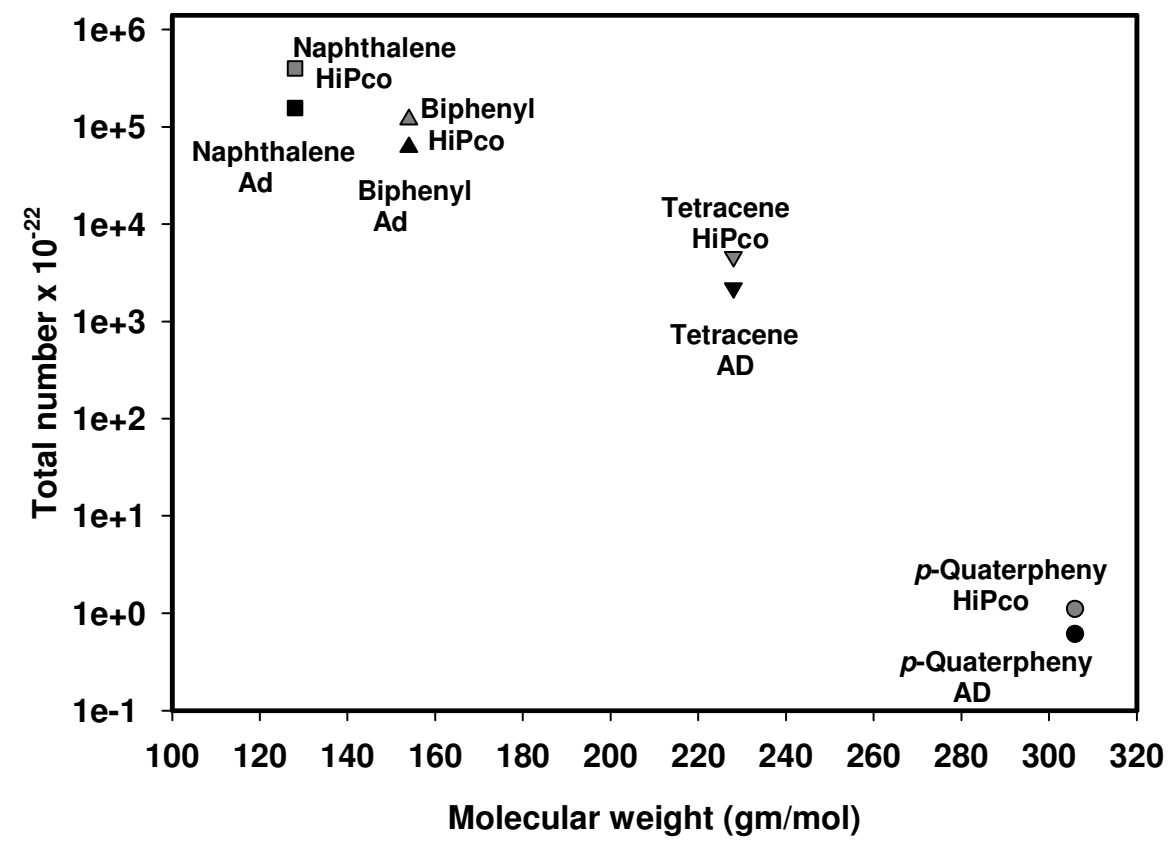

Figure 8 


\section{TABLE OF CONTENTS IMAGE:}

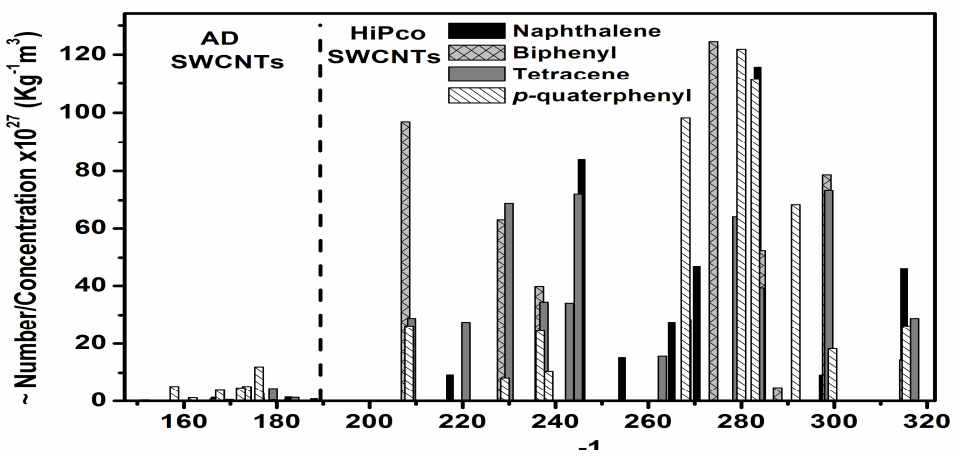

